\title{
Depth profiling of photodegraded wood surfaces by confocal Raman microscopy
}

\author{
Toru Kanbayashi ${ }^{1} \cdot$ Yutaka Kataoka ${ }^{1}$ - Atsuko Ishikawa ${ }^{1}$ Masahiro Matsunaga ${ }^{1} \cdot$ Masahiko Kobayashi $^{1}$. \\ Makoto Kiguchi ${ }^{1}$
}

Received: 8 December 2017 / Accepted: 5 January 2018 / Published online: 24 January 2018

(C) The Japan Wood Research Society 2018

Keywords Confocal Raman microscopy $\cdot$ Depth profile $\cdot$ Photodegradation $\cdot$ Weathering $\cdot$ Wood

\section{Introduction}

Weathering leads to rapid depolymerization of the chemical components and degradation of the cellular structure of wood $[1,2]$. These changes are facilitated by a combination of solar radiation, moisture, temperature, air pollutions, and other factors. Among them, solar radiation is most damaging to wood because ultraviolet (UV) rays cause free radical oxidation and the reactions that significantly deteriorate the constituents of wood $[1,3]$.

Light-induced degradation, also called photodegradation, of wood occurs in its surface layer. An earlier study that employed electron spin resonance (ESR) estimated that UV and visible light penetrate wood to a depth of 75 and $200 \mu \mathrm{m}$, respectively [4]. Later works by Kataoka et al. reported that, on the basis of Fourier transform infrared (FTIR) microscopy measurements, that the depth of light penetration into wood and the spreading rate of the degradation layer depend on the wavelength of light source [5], exposure time [6,7], and wood density [8]. In addition, several other tools have also been employed to investigate the depth analysis of photodegraded wood [9-12]. Recently, high spatial resolution IR microscopy techniques such as infrared scanning near-field optical microscopy (IR-SNOM) and atomic force microscopy-based infrared spectroscopy (AFM-IR) have been developed, but there are only a few applications of these techniques to wood samples [13, 14].

Confocal Raman microscopy is useful for evaluating the molecular structure of various materials with a high spatial

Toru Kanbayashi

kanbayashi@ffpri.affrc.go.jp

1 Forestry and Forest Products Research Institute, Forest Research and Management Organization, Matsunosato 1, Tsukuba, Ibaraki 305-8687, Japan resolution [15]. In recent years, this technique has come to be used in topochemical studies of native $[16,17]$ and modified wood [18, 19]. Although some Raman methods such as FT-Raman [20] and UV resonance Raman spectroscopy [21] have been applied for monitoring of wood photodegradation, micro-scale investigation using the confocal system has not yet been performed. Therefore, in the present work, confocal Raman microscopy, which is helpful in investigating the micro-distribution of functional groups in wood cell walls, has been applied to the depth profiling analysis of lightexposed wood surfaces.

\section{Materials and methods}

Wood blocks measuring 140 (longitudinal) $\times 25($ radial $) \times 9$ (tangential) $\mathrm{mm}$ were cut from the sapwood of air-dried sugi (Cryptomeria japonica D. Don). The radial surface of each block was smoothed with a wood planer and then exposed to artificial sunlight from a xenon arc light source $\left(0.51 \mathrm{~W} / \mathrm{m}^{2}\right.$ at $340 \mathrm{~nm}$ ) in a weather-o-meter (Ci4000, Atlas, USA) with a black panel temperature of $65^{\circ} \mathrm{C}$ and chamber temperature of $38{ }^{\circ} \mathrm{C}$. After a 500 -h exposure (no rain), $15-\mu \mathrm{m}$-thick cross sections used for Raman measurement (Fig. 1) were prepared on a sliding microtome.

The depth profiling analysis was conducted using a confocal microRaman system (LabRAM ARAMIS, Horiba Jobin Yvon, France) equipped with a microscope (BX41, Olympus, Japan), a 100 $\times$ objective lens (UPLSAPO, NA $=1.4$, Olympus), and a diode-pumped solid-state laser (Ventus VIS 532, $\lambda=532 \mathrm{~nm}$, Laser Quantum, UK). The incident laser power and the laser spot size on the sample were approx. $13 \mathrm{~mW}$ and $0.5 \mu \mathrm{m}$, respectively. Scattered Raman light was detected by a charge-coupled device (CCD) camera placed behind a $600-$ lines/mm grating. The Raman spectra were 
Wood block Sectioning Depth profiling

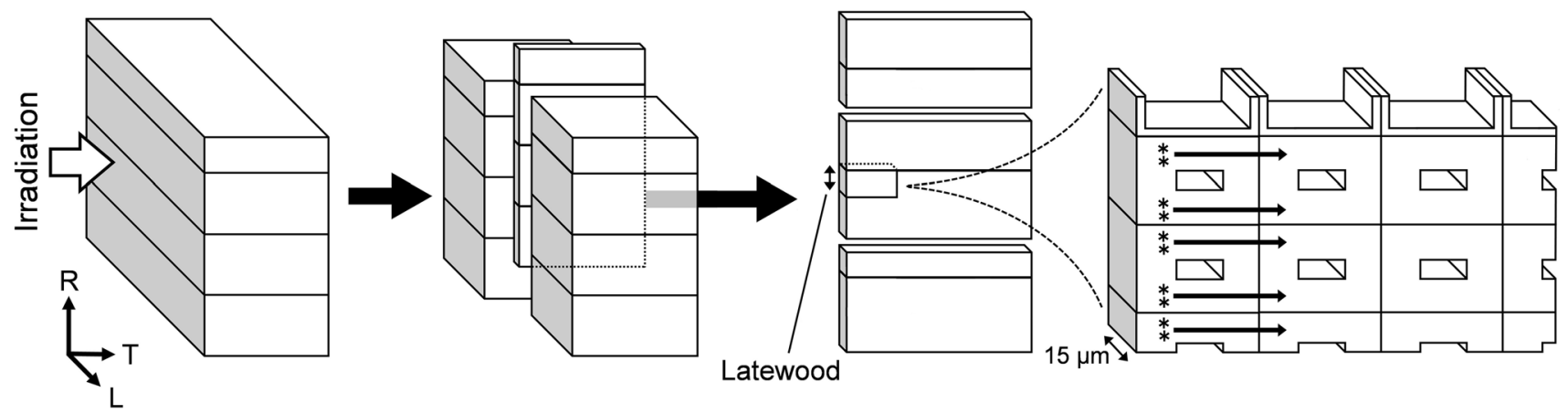

Fig. 1 Procedure to obtain thin cross section along the light-exposed sample and the enlarged view of measurement area for depth profile analysis. $L$ longitudinal, $R$ radial, $T$ tangential, asterisk excitation laser irradiated position

recorded in ten cycles with each cycle containing a $1 \mathrm{~s}$ integration time for one spot. Ten spectra were obtained and averaged, and the averaged spectra from ten different locations were again averaged. All the measurement positions were located on latewood, as shown in Fig. 1.

For the data acquisition and analysis, LabSpec 5 software (Horiba Jobin Yvon) was used. To remove the background from the fluorescence, the raw spectral data were baselinecorrected. Raman spectra were normalized by the intensity of the band at $1096 \mathrm{~cm}^{-1}$ due to $\mathrm{C}-\mathrm{O}$ and $\mathrm{C}-\mathrm{C}$ stretching in polysaccharides [22].

\section{Results and discussion}

The Raman depth profiling spectra obtained from unexposed and exposed latewood are shown in Fig. 2. Significant changes in the Raman spectra were observed close to the surface. An obvious reduction in the intensities of the lignin bands at 1597 and $1139 \mathrm{~cm}^{-1}$ assigned to aromatic ring stretching and coniferyl aldehyde structure [23], respectively, is observed. This was accompanied by an increase in the intensity of the carbonyl stretching [24] band at $1745 \mathrm{~cm}^{-1}$. These spectral changes imply that degradation of lignin structures and formation of new carbonyl groups occurred in the wood surface during $500 \mathrm{~h}$ of exposure.

To determine the maximum depth of photodegradation in latewood, the intensity ratios of the Raman bands at 1139, 1597 and $1745 \mathrm{~cm}^{-1}$ against the reference band at $1096 \mathrm{~cm}^{-1}$ were calculated and these are shown in Fig. 3. The filled symbols refer to statistically significant changes in intensity, and provide a measure of the maximum depth of photodegradation. Significant changes in the aromatic $\left(1597 \mathrm{~cm}^{-1}\right)$, carbonyl $\left(1745 \mathrm{~cm}^{-1}\right)$ and coniferyl aldehyde $\left(1139 \mathrm{~cm}^{-1}\right)$ band intensity can be detected in latewood at the depths of 100-145, 249-285 and 426-496 $\mu \mathrm{m}$, respectively.

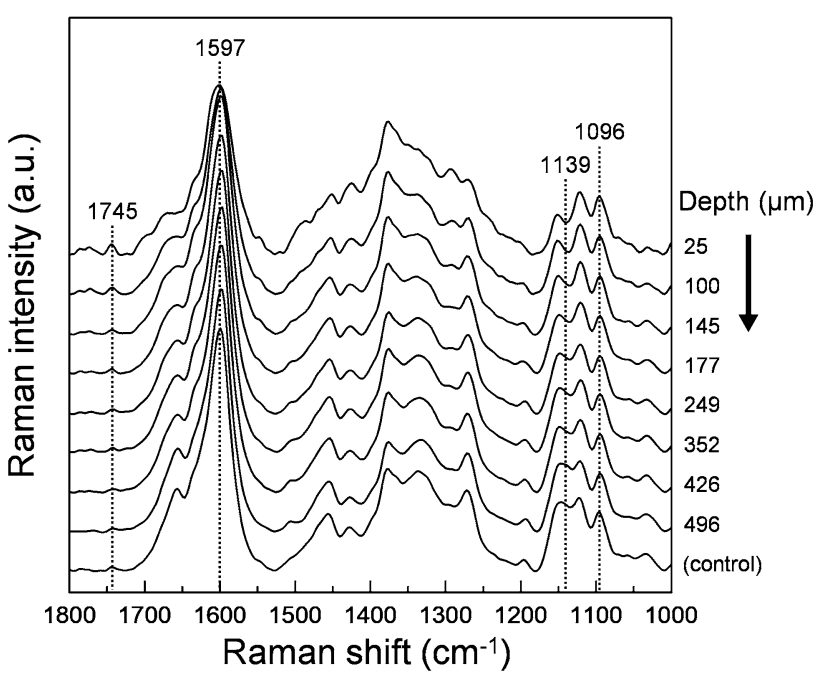

Fig. 2 Raman spectra for sugi latewood before (unexposed control) and after $500 \mathrm{~h}$ of exposure to artificial sunlight at different depths

The degradation depth assessed by monitoring the carbonyl band (Fig. 3b) was somewhat greater than that observed in previous experiments using FT-IR microscopy [8]. This is due, in part, to the differences in measuring the position and exposed conditions because the depth of light penetration into wood and the spreading rate of degradation layer depends on the density of wood and the intensity and light exposure time [6-8].

The difference between the measured values obtained by FT-IR and Raman microscopy may also be related to the scale range of the instruments. The spatial resolution of Raman microscopy was higher than that of FT-IR microscopy. Raman depth profiling spectra in this study were recorded at each interval several tens of micrometers with a spot diameter of approx. $0.5 \mu \mathrm{m}$, while FT-IR depth profiling spectra in previous study were recorded 

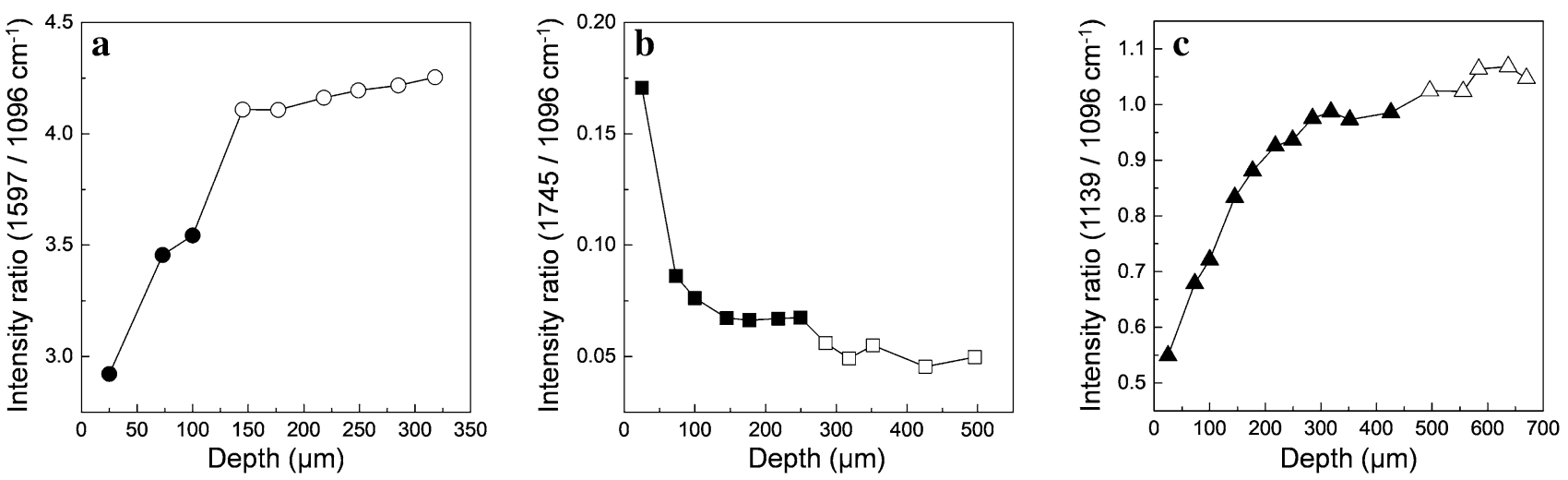

Fig. 3 Changes in Raman intensities at a $1597 \mathrm{~cm}^{-1}$, b $1745 \mathrm{~cm}^{-1}$ and $\mathbf{c} 1139 \mathrm{~cm}^{-1}$ as a function of depth for sugi latewood exposed to artificial sunlight. Filled symbols indicate that significant changes

at intervals of approx. $50 \mu \mathrm{m}$ with a focusing area of 50 (depth) $\times 200$ (width) $\mu \mathrm{m}$. The boundary between degraded and undegraded areas can be separated with submicron precision by Raman microscopy leading to more accurate monitoring of photodegradation reactions that occur in wood surfaces.

It is important to highlight that the degradation depth estimated by the band of coniferyl aldehyde was extremely deep (Fig. 3c). A previous study that used resonance Raman spectroscopy revealed that coniferyl aldehyde is a photosensitive chromophore and as such, the structure of lignin is rapidly decomposed by light exposure [25]. In addition, blue light penetrates wood more deeply than UV light and is capable of bleaching wood, without causing marked changes in the IR spectra [5]. It is possible that the blue and longer wavelength light-induced partial degradation of lignin structures, such as the coniferyl aldehyde unit, which is undetectable by FT-IR, was reflected on the Raman spectra and, therefore, the degradation layer developed extremely deep into the region and could be detected. In a follow up report, we will investigate the effects of the wavelength of exposed light on degradation of wood constituents by Raman method.

Acknowledgements This work was supported by JSPS KAKENHI Grant Number 17K15299. The authors wish to thank the Kyoto Integrated Science and Technology Bio-Analysis Center (KIST-BIC) for its assistance with the Raman microscopic analysis.

\section{References}

1. Feist WC, Hon DNS (1984) Chemistry of weathering and protection. In: Rowell RM (ed) The chemistry of solid wood. American Chemical Society, Washington DC, pp 401-451

2. Evans PD, Thay PD, Schmalzl KJ (1996) Degradation of wood surfaces during natural weathering. Effects on lignin and cellulose and on the adhesion of acrylic latex primers. Wood Sci Technol 30:411-422 in peaks occurred as a result of light exposure $(n=20$, difference between unexposed controls and exposed samples assessed determined by Smirnov-Grubbs test with a significance level of 0.05 )

3. Williams RS (2005) Weathering of wood. In: Rowell RM (ed) Handbook of wood chemistry and wood composites. CRC Press, Boca Raton

4. Hon DNS, Ifju G (1978) Measuring penetration of light into wood by detection of photo-induced free radicals. Wood Sci 11:118-127

5. Kataoka Y, Kiguchi M, Williams RS, Evans PD (2007) Violet light causes photodegradation of wood beyond the zone affected by ultraviolet radiation. Holzforschung 61:23 - 27

6. Kataoka Y, Kiguchi M (2001) Depth profiling of photo-induced degradation in wood by FT-IR microspectroscopy. J Wood Sci $47: 325-327$

7. Kataoka Y, Kiguchi M, Evans PD (2004) Photodegradation depth profile and penetration of light in Japanese cedar earlywood (Cryptomeria japonica D. Don) exposed to artificial solar radiation. Surf Coat Int B Coat Trans 87:187-193

8. Kataoka Y, Kiguchi M, Fujiwara T, Evans PD (2005) The effects of within-species and between-species variation in wood density on the photodegradation depth profiles of sugi (Cryptomeria japonica) and hinoki (Chamaecyparis obtusa). J Wood Sci 51:531-536

9. Park BS, Furuno T, Uehara T (1996) Histochemical changes of wood surfaces irradiated with ultraviolet light. Mokuzai Gakkaishi 42:1-9

10. Horn BA, Qiu J, Owen NL, Feist WC (1994) FT-IR study of weathering effects in western redcedar and southern pine. Appl Spectrosc 48:662-668

11. Yamauchi S, Sudiyani Y, Imamura Y, Doi S (2004) Depth profiling of weathered tropical wood using Fourier transform infrared photoacoustic spectroscopy. J Wood Sci 50:433-438

12. Jirous-Rajkovic V, Turkulin H, Miller ER (2004) Depth profile of UV-induced wood surface degradation. Surf Coat Int B Coat Trans 87:241-247

13. Yamagishi T, Aizawa K, Yamada T, Matsumoto Y (2013) IRSNOM analysis of occluding substances in lumina of xylem elements in sapwood of Quercus serrata attacked by Platypus quercivorus. Anal Sci 29:411-415

14. Wang X, Deng Y, Li Y, Kjoller K, Roy A, Wang S (2016) In situ identification of the molecular-scale interactions of phenol-formaldehyde resin and wood cell walls using infrared nanospectroscopy. RSC Adv 6:76318-76324

15. Smith E, Dent G (2005) Modern Raman spectroscopy: a practical approach. Wiley, Chichester 
16. Gierlinger N, Schwanninger M (2006) Chemical imaging of poplar wood cell walls by confocal Raman microscopy. Plant Physiol 140:1246-1254

17. Agarwal UP (2006) Raman imaging to investigate ultrastructure and composition of plant cell walls: distribution of lignin and cellulose in black spruce wood (Picea mariana). Planta 224:1141-1153

18. Kanbayashi T, Miyafuji H (2015) Raman microscopic analysis of wood after treatment with the ionic liquid, 1-ethyl-3-methylimidazolium chloride. Holzforschung 69:273-279

19. Keplinger T, Cabane E, Chanana M, Hass P, Merk V, Gierlinger $\mathrm{N}$, Burgert I (2015) A versatile strategy for grafting polymers to wood cell walls. Acta Biomater 11:256-263

20. Cogulet A, Blanchet P, Landry V (2016) Wood degradation under UV irradiation: a lignin characterization. J Photochem Photobiol B Biol 158:184-191
21. Pandey KK, Vuorinen T (2008) UV resonance Raman spectroscopic study of photodegradation of hardwood and softwood lignins by UV laser. Holzforschung 62:183-188

22. Wiley JH, Atalla RH (1987) Band assignments in the Raman spectra of celluloses. Carbohydr Res 160:113 - 129

23. Agarwal UP, McSweeny JD, Ralph SA (2011) FT-Raman investigation of milled wood lignins: softwood, hardwood, and chemically modified black spruce lignins. J Wood Chem Tech 31:324-344

24. Kenton RC, Rubinovitz RL (1990) FT-Raman investigations of forest products. Appl Spectrosc 44:1377-1380

25. Jääskeläinen AS, Saariaho AM, Vyörykkä J, Vuorinen T, Matousek P, Parker AW (2006) Application of UV-Vis and resonance Raman spectroscopy to study bleaching and photoyellowing of thermomechanical pulps. Holzforschung 60:231-238 